\title{
A VIABILIDADE DO IMPOSTO SOBRE O VALOR DA TERRA: ANÁLISE TEÓRICA E EMPÍRICA, E SEU CONTEXTO NA REFORMA TRIBUTÁRIA ${ }^{1}$
}

\author{
Claudia M. De Cesare ${ }^{2}$ \\ Cintia Estefania Fernandes ${ }^{3}$ \\ Gelson Santos Oliveira ${ }^{4}$ \\ Pedro Humberto B. Carvalho Junior ${ }^{5}$
}

\section{INTRODUÇÃO}

O relatório da Proposta de Emenda Constitucional (PEC) no 110/2019, cujo objeto é a reformulação do Sistema Tributário Nacional (STN), tem sido discutido em diferentes fóruns e grupos que analisam os encaminhamentos relacionados à reforma tributária. Não obstante as 141 emendas abordadas no relatório, propóem-se alteraçôes adicionais ao projeto de reforma tributária. Entre estas alteraçôes, é recomendado que a base de cálculo do IPTU seja modificada para o valor da terra desconsiderando as construçóes (item xix, p. 28). ${ }^{6}$ É, também, sugerido o estabelecimento, por intermédio de lei complementar, de alíquotas mínimas e máximas para o imposto proposto, limites para a concessão de isençôes e benefícios fiscais, e critérios para a avaliação dos imóveis.

\footnotetext{
1. DOI: http://dx.doi.org/10.38116/brua24art7

2. Pesquisadora e consultora. PhD pela Universidade de Salford, Inglaterra; conselheira do International Property Tax Institute (IPTI); membro do Teaching Faculty do Lincoln Institute of Land Policy; e professora do Programa Nacional de Capacitação das Cidades e da Universidade Federal do Rio Grande do Sul (UFRGS).

3. Procuradora de Curitiba. Doutora em gestão urbana pela Pontifícia Universidade Católica do Paraná (PUCPR); mestra em direito do Estado, direito tributário pela Universidade Federal do Paraná (UFPR); especialista em políticas de solo urbano pelo Lincoln Institute of Land Policy (Massachusetts-Estados Unidos); membro do Teaching Faculty do Lincoln Institute of Land Policy; professora do Programa Nacional de Capacitação das Cidades (Ministério do Desenvolvimento Regional - MDR), do Instituto Brasileiro de Estudos Tributários (IBET), da Academia Brasileira de Direito Constitucional (ABDConst) e do Centro Universitário de Curitiba (UniCuritiba). Presidente da Comissão de Direito à Cidade (Ordem dos Advogados do Brasil do Paraná - OAB/PR) e vice-presidente da Comissão Nacional de Direito Urbanístico da OAB.

4. Auditor fiscal da Secretaria Municipal da Fazenda de Salvador; membro da Coordenação Técnica da Planta Genérica de Valores; ex-gerente de auditoria fiscal do Grupo Especializado de Imposto Predial e Territorial Urbano (IPTU) e conselheiro do Conselho Municipal de Contribuintes; especialista em direito tributário - Fundação Faculdade de Direito (Universidade Federal da Bahia - UFBA); planejamento urbano e gestão de cidades (Universidade Salvador - Unifacs); e professor em cursos e treinamentos em tributação imobiliária.

5. Técnico de planejamento e pesquisa na Diretoria de Estudos e Relações Econômicas e Políticas Internacionais (Dinte) do Ipea. PhD em política tributária pela Universidade de Pretória, África do Sul.

6. Disponível em: <https://legis.senado.leg.br/sdleg-getter/documento?dm=8050102\&ts=1594007105613\&disposition=inline>.
} 
A viabilidade desta proposta, no entanto, deve ser cuidadosamente analisada. Alteraçóes na política tributária devem ser fundamentadas na avaliação dos seus impactos, visando evitar mudanças que reduzam as receitas municipais, colocando em risco a continuidade da prestação de serviços públicos básicos, ou que resultem em regressividade na distribuição da carga tributária para a maior parte dos contribuintes. Em especial, é necessário contar com análises empíricas dedicadas a responder satisfatoriamente as seguintes questôes centrais.

1) No contexto atual, um imposto exclusivamente sobre o valor da terra urbana, desconsiderando as construçóes, poderia apresentar potencial de arrecadação semelhante a um imposto cuja base de cálculo seja o valor integral do imóvel (terra e construçóes)?

2) Em caso positivo, qual seria a alíquota que compensaria a perda de receita produzida pela exclusão das construçóes? Haveria o risco de esta alíquota ser confiscatória para parte dos imóveis? Por sua vez, sem alteração das alíquotas, qual seria a perda na arrecadação?

3) Em comparação ao IPTU, o imposto sobre o valor da terra irá melhorar ou piorar a relaçáo entre o ônus tributário e a capacidade contributiva das famílias? Haverá progressividade ou regressividade na redistribuição da carga tributária?

4) Qual o risco de as unidades de alto padráo localizadas em condomínios verticais pagarem um imposto simbólico?

5) Como seria o impacto do imposto sobre o valor da terra nos segmentos não residenciais (comércio, indústria e serviços)? Lojas e demais estabelecimentos mercantis horizontais sofreriam uma carga tributária desproporcional em comparação com unidades comerciais localizadas em condomínios verticais, como salas e consultórios?

6) O imposto sobre o valor da terra incentivaria a demolição desnecessária de prédios e imóveis que apresentam condiçóes satisfatórias de habitabilidade, visando incentivar que as cidades sejam mais compactas?

7) Considerando o perfil fortemente heterogêneo dos municípios brasileiros, quanto o valor da terra representa em relação ao valor integral do estoque imobiliário nas diferentes cidades e tipos de imóveis?

8) Considerando ainda que a maioria dos municípios nos quais o IPTU é uma receita relevante tem um perfil eminentemente urbano, qual a proporção de terrenos baldios nestas cidades?

9) Em cidades consolidadas, é mais viável estimar com precisão o valor dos imóveis construídos ou o seu valor desconsiderando as construções?

10) E quanto ao cadastro imobiliário, o imposto sobre o valor da terra permitiria a exclusão das construçôes para resultar em um sistema mais simplificado?

11) Com relação à legislação vigente, existem mecanismos para combater a especulação imobiliária no Brasil?

Este artigo busca analisar a viabilidade de introduzir um imposto sobre o valor da terra no contexto brasileiro, levando em conta aspectos legais, questôes relativas a sua implementação e benefícios potenciais. $\mathrm{O}$ artigo está dividido em cinco seçôes. Além desta primeira seção introdutória, a segunda seção abrange a revisão da literatura relacionada ao imposto sobre o valor da terra (conhecido como land value taxation). A terceira examina os resultados de análises empíricas sobre a sua aplicabilidade no Brasil, mais especificamente na cidade de Porto Alegre. A quarta seção analisa o atual desempenho dos dois impostos recorrentes 
sobre a propriedade imobiliária: o IPTU e o Imposto sobre a Propriedade Territorial Rural (ITR). Por fim, a quinta seção apresenta as principais conclusôes e recomendações da análise.

\section{IMPOSTO SOBRE O VALOR DA TERRA: FUNDAMENTAÇÃO TEÓRICA}

Economistas clássicos do século XIX, incluindo David Ricardo, reconheceram que o imposto sobre o valor da terra não causa distorçóes econômicas (Netzer, 1998). Com base fundamentalmente nos estudos de John Locke e Henry George, a teoria liberal fornece as principais premissas econômicas para sua fundamentação, que resultam do reconhecimento de que recursos naturais - terra, ar ou água - são bens públicos que pertencem a todos, justificando assim a arrecadação integral da renda que poderia ser extraída destes bens pelo Estado (Plassmann, 1997). Tideman (1999) enfatiza que é o fluxo, em vez do estoque, dos recursos naturais, isto é, a renda extraída destes bens que deve ser alocada igualmente para a comunidade.

No livro Progresso e Pobreza, publicado em 1879, Henry George defende a aplicação de um imposto único sobre o valor da terra a fim de compensar a injustiça causada pela propriedade privada. $\mathrm{O}$ autor explica que a renda da terra pode ser entendida como uma fonte de enriquecimento sem causa, visto que não é uma consequência de açóes realizadas pelos seus proprietários. Inspirados pelas ideias de Henry George, nove economistas foram agraciados com o Prêmio Nobel em economia. ${ }^{7}$

Do ponto de vista econômico, a tributação sobre o valor da terra desconsiderando as construções é enaltecida pelo fato de que este imposto não distorce decisôes econômicas em razão de a oferta da terra ser fixa (Brueckner, 1986). Em contraste, decisóes sobre investimentos em construção ou equipamentos podem variar devido a maior ou menor incidência tributária. Como observam De Cesare et al. (2003), a terra apresenta as seguintes particularidades:

- é um recurso natural inesgotável que não deprecia com o tempo;

- devido a sua imobilidade, a demanda excessiva em certa localização não pode ser compensada pelo seu excesso em outra área;

- em virtude de sua visibilidade, é um bem que não pode ser omitido, embora a existência de um cadastro territorial atualizado possa ser um grande desafio; e

- é um insumo primordial para a satisfação de necessidades básicas de moradia e trabalho.

Seu valor é determinado exclusivamente pela demanda local, embora seja influenciado por fatores externos, tais como mudanças demográficas, crescimento econômico, política de crédito habitacional e nível de investimento internacional. Para George (1996), o valor da terra é fundamentalmente resultante de esforços coletivos, como gastos públicos em infraestrutura urbana e serviços básicos que "tendem a aumentar dramaticamente o valor dos imóveis beneficiados" (Lichfield e Connellan, 1997). Além disso, o valor da terra está relacionado ao seu potencial construtivo.

O quadro 1 classifica em três grupos os principais argumentos citados na literatura para justificar a instituição do imposto sobre o valor da terra.

7. Paul Samuelson (1970); Milton Friedman Nobel (1976); Herbert Simon (1978); James Tobin (1981); Franco Modigliani (1985); James Buchanan (1986); Robert Solow (1987); William Vickrey (1996); e Joseph Stiglitz (2001). 
QUADRO 1

Argumentos em favor do imposto sobre o valor da terra

\begin{tabular}{|c|c|}
\hline \multirow{2}{*}{ Grupo 1: éticos e filosóficos } & - Igualdade de direitos sobre recursos naturais \\
\hline & - Oportunidade para a captura de valor \\
\hline \multirow{6}{*}{ Grupo 2: econômicos } & - Neutralidade em termos de eficiência econômica ${ }^{1}$ \\
\hline & - Inexistência de perdas de eficiência (peso-morto)² \\
\hline & - Estímulo ao investimento ${ }^{3}$ \\
\hline & - Redução dos custos da cidade (cidades compactas) \\
\hline & - Incidência econômica progressiva (imposto é pago pelo dono da terra) ${ }^{4}$ \\
\hline & - Melhor alocação da terra \\
\hline \multirow{3}{*}{ Grupo 3: administrativos } & - Simplificação do cadastro \\
\hline & - Impossibilidade de evasão tributária \\
\hline & - Menor custo para a avaliação dos imóveis \\
\hline
\end{tabular}

Fonte: De Cesare et al. (2003).

Notas: ${ }^{1}$ A neutralidade do imposto sobre o valor da terra é relacionada ao fato de o imposto não alterar decisões quanto à intensidade de densificação ou momento de desenvolvimento das áreas. Em outras palavras, decisões consideradas ótimas antes da aplicação do imposto permanecem ótimas após a sua instituição.

${ }^{2}$ Tendem a ser observadas perdas de eficiência (peso-morto) em impostos que incidem sobre bens de oferta elástica, uma vez que o imposto aumenta o valor de mercado do bem, desincentivando o consumo.

${ }^{3}$ Autores da escola neoclássica como Bentick (1979), Mills (1998) e Oates e Schwab (1997) argumentam que o imposto sobre a terra não estimula o investimento, porque o valor da terra no presente já é dado pelo seu "maior e melhor uso".

${ }^{4}$ A teoria econômica demonstra que, quando um imposto é tributado em um bem de oferta constante, independentemente do seu preço, a carga tributária é paga pelo proprietário do bem, que é incapaz de transferir o imposto aos usuários por intermédio da redução da sua oferta.

No entanto, Netzer (1998) alerta que o sucesso político da teoria de Henry George é extremamente limitado. Apesar de o imposto recorrente sobre bens imóveis existir na grande maioria dos países, apenas a Dinamarca, a Austrália e a Estônia estabeleceram um imposto puro ao valor da terra (Pinto, 2020). No caso da Austrália, o imposto imobiliário estadual incide apenas sobre o valor da terra, enquanto o imposto municipal incide sobre o valor integral dos imóveis. ${ }^{8}$ A Jamaica também introduziu o imposto sobre o valor da terra a fim de motivar a reforma agrária. Possivelmente, devem existir outros países pequenos que optaram por essa alternativa. Na Nova Zelândia, a sua reduzida aceitabilidade resultou na inclusão do valor das construçóes em 1992. Ainda, é importante notar que tanto a Austrália como a Nova Zelândia são países de baixa densidade demográfica. Nos Estados Unidos, a grande maioria dos municípios emprega o valor integral do imóvel, incluindo as construçóes, exceto em municípios do estado da Pensilvânia.

Cabe a reflexáo sobre quais os fatores que explicam o alto grau de rejeição do imposto sobre o valor da terra no âmbito mundial. Obstáculos à sua implementaçáo e falta de evidências empíricas dos argumentos apresentados no quadro 1 são discutidos na sequência.

\subsection{Falta de comprovação empírica sobre os efeitos econômicos}

As evidências empíricas sobre os efeitos de excluir o valor das construçóes do imposto imobiliário na atividade de construção são limitadas. Estudos realizados entre 1980 e 2000 apresentam resultados contraditórios. ${ }^{9}$ Como enfatizado por Plassmann (1997), não há resultados consistentes que indiquem alteraçôes nas decisôes relacionadas à atividade da construção.

8. Disponível em: <http://www1.worldbank.org/publicsector/decentralization/June2003Seminar/Australia.pdf>.

9. São eles: Edwards (1984); Mathis e Zech (1982); Weir e Peters (1986); Lusht (1992); Tideman e Johnson (1995); Oates e Schwab (1997); e Plassmann (1997). Lusht (1992) e Plassmann (1997) conseguiram identificar um impacto positivo do imposto na atividade de construção. 


\subsection{Efeitos controversos}

Andelson (2000) alerta sobre o risco de superdensificação urbana como efeito controverso desta política. Atualmente, as preocupações com densificação populacional excessiva estão em pauta em consequência do risco de proliferação de doenças contagiosas, entre as quais merece destaque a Covid-19.

Com base no posicionamento de diferentes urbanistas americanos, Flint (2020) alerta para transformaçôes urbanas prováveis no período pós-pandemia, abrangendo: aumento de espaços abertos nos imóveis; introdução de melhores sistemas de ventilaçáo; viabilização de divisôes flexíveis que permitam maior privacidade; reduçáo no número de trabalhadores nos imóveis não residenciais em função do trabalho remoto; e revalorização da vida nos subúrbios onde as famílias podem desfrutar de mais espaço. No Brasil, com a intensificação do trabalho remoto, observou-se a transferência de muitas famílias dos seus apartamentos com espaço limitado nas cidades para casas de veraneio nos balneários ou na serra nos segmentos de renda média-alta e alta. Embora ainda seja cedo para assegurar quais as transformaçôes urbanas terão caráter mais permanente, a tendência é que o enfrentamento traumático da Covid-19 motive a redução da densificação das áreas urbanas, desafiando a máxima de que as cidades devem ser compactas.

\subsection{Desvinculação da capacidade contributiva e risco de perda de receita}

McCluskey e Williams (1999) advertem que um imposto sobre o valor da terra limita significativamente a magnitude da base de cálculo, excluindo parte substancial da riqueza, principalmente em cidades urbanas consolidadas. Embora a perda de receita possa ser compensada pela elevação da alíquota, é imprescindível assegurar a existência de capacidade contributiva para arcar com o ônus tributário nas diferentes classes de imóveis devido à desvinculação entre o imposto e a riqueza. Em virtude da necessidade de renda monetária líquida para o pagamento do imposto, a inadimplência tende a aumentar quando a base de cálculo é desvinculada da renda do contribuinte (UN-Habitat, 2011), como ocorre com o imposto sobre o valor da terra.

\subsection{Receio de confisco e pressões políticas}

Andelson (2000) alerta que impostos com alíquotas elevadas sobre a terra tendem a ser vistos como confiscatórios, com base no argumento de que a terra foi adquirida de boa-fé e que a legislação garante os direitos de propriedade. Plassmann (1997) reconhece que o imposto pode criar injustiças e resultar em fortes pressôes políticas.

\subsection{Falácia nos argumentos de cunho administrativo}

Os argumentos sobre a redução do custo administrativo em apoio ao imposto sobre o valor da terra são questionáveis. Por exemplo, a afirmaçáo de que é impossível a ocorrência de evasão tributária não é verdadeira para cidades marcadas por assentamentos informais e parcelamentos irregulares. Em termos tributários, a maior dificuldade nestes casos consiste em identificar o contribuinte. Este desafio permanece inalterado independentemente de a base de cálculo do tributo ser o valor integral do imóvel ou o valor da terra desconsiderando as construçóes.

A hipótese de simplificação do cadastro deve também ser descartada. O poder público necessita monitorar o estoque imobiliário e seu crescimento para fins de planejamento territorial, instituição de instrumentos de política urbana e fiscalização das declaraçôes do 
imposto sobre as transferências de imóveis. A exclusão das construçôes das bases cadastrais seria um retrocesso, podendo ser até inviável sem a realização de um recadastramento completo dos imóveis, o que aumentaria o custo de transição do modelo.

A redução no custo das avaliaçóes seria parcial. Por exemplo, os observatórios do mercado imobiliário ${ }^{10}$ necessitam ser mantidos para viabilizar a aplicação do método residual na avaliação dos terrenos; ${ }^{11}$ servir de base em avaliaçóes desenvolvidas para fins de Imposto sobre a Transmissão de Bens Imóveis (ITBI), desapropriaçôes e concessóes de uso; e embasar decisões de políticas urbanas. Cabe ainda notar que a avaliação de terrenos em cidades urbanas consolidadas é mais difícil que a avaliação de bens cuja oferta é abundante no mercado de imóveis.

\subsection{Iniquidades de caráter avaliatório}

Observa-se forte consenso quanto à dificuldade de avaliar com precisão o valor da terra excluindo as edificaçóes (Lichfield e Connellan, 1997; McCluskey e Franzsen, 1999). Conforme Arnott (2000, p. 25, tradução nossa), "não há formas consistentes de decompor o valor de um imóvel em terra e benfeitorias”. O argumento é especialmente verdadeiro para cidades urbanas consolidadas onde inexistem terrenos baldios em regiốes centrais, polos comerciais e outras áreas fortemente densificadas. Segundo Mills (1998), regras arbitrárias tendem a ser utilizadas, resultando em iniquidades de caráter avaliatório que prejudicam inclusive a eficiência econômica do imposto ao valor da terra.

\subsection{Falta de transparência, arbitrariedade e prejuízo ao direito de contestação}

Quanto aos imóveis edificados, os contribuintes conhecem ou têm condições de conhecer o preço dos seus imóveis. No imposto sobre o valor da terra, o exercício dos direitos à contestação por parte dos contribuintes de imóveis edificados fica prejudicado nas vias administrativas ou judiciais, devido à ausência de informação sobre preços da terra em imóveis construídos.

\subsection{Percepção de regressividade}

O imposto sobre o valor da terra tende a ser percebido como injusto pelos contribuintes. Como observa Reece (1992), existe iniquidade entre quem possui bens de valor semelhante, bem como tende a beneficiar contribuintes que possuem maior capacidade contributiva. A seguir encontram-se alguns exemplos ilustrativos de situaçôes relacionadas à percepção de injustiça.

- A depreciação das construções é ignorada no cálculo do imposto sobre o valor da terra. Portanto, o proprietário de um apartamento novo pagaria imposto idêntico ao dono de um apartamento antigo em mesma localização.

- Os impostos lançados para dois prédios de mesma área de terreno, situados na mesma face de quarteirão, são iguais, independentemente do número de pavimentos em cada um deles. Desta forma, imóveis antigos, com poucos andares, e de baixo valor, pagariam imposto significativamente maior que imóveis novos, de padrão superior, que estejam localizados em prédio com muitos andares.

10. Sistema de informação destinado à coleta e ao armazenamento contínuo de dados de mercado, incluindo preços de oferta e venda de imóveis, cujo propósito é monitorar o mercado imobiliário e fornecer os dados necessários para a aplicação de diferentes métodos de avaliação de imóveis.

11. Metodologia de estimação do valor da terra de um imóvel construído, que consiste em extrair o custo da edificação e todas as benfeitorias do valor de mercado do imóvel, resultando, como resíduo, no valor da terra. 
As situaçóes citadas ilustram a perda de conexão entre o imposto e a capacidade contributiva. Por razóes que fogem ao escopo deste artigo, ${ }^{12}$ as cidades brasileiras consolidadas apresentam um perfil de ocupação altamente heterogêneo. A figura 1 mostra casos de condomínios verticais situados na mesma rua na cidade de Porto Alegre. A aplicaçáo do imposto sobre o valor da terra desconsiderando as construçóes resultaria em forte regressividade principalmente para unidades em condomínios verticais, onerando apartamentos pequenos e antigos.

FIGURA 1

Prédios próximos de características heterogêneas no bairro Menino Deus em Porto Alegre

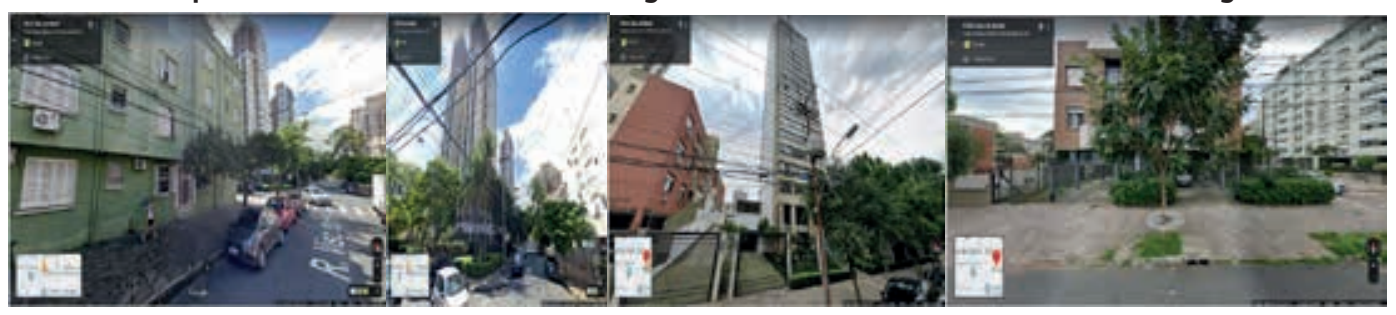

Elaboração dos autores.

\section{DISTRIBUIÇÃO DA CARGA TRIBUTÁRIA}

Além de avaliar o impacto do imposto sobre o valor da terra na atividade de construção, a viabilidade da sua instituição depende da redistribuição da carga tributária nos diferentes segmentos de imóveis. Esta análise é particularmente relevante no caso de municípios altamente densificados, nos quais grande parte da população mora ou trabalha em prédios em condomínios verticais.

O único estudo a respeito da distribuição da carga tributária de um eventual imposto sobre o valor da terra no Brasil foi desenvolvido por De Cesare et al. (2003). Este estudo analisa o impacto da mudança da base de cálculo do IPTU para o valor da terra para imóveis residenciais na cidade de Porto Alegre.

Uma das premissas para realizar a análise foi assumir que a transição deveria ser neutra, isto é, não haveria nem perda nem incremento de receita no lançamento global do imposto. O estudo contemplou duas situaçóes: i) receita a ser aferida pelo imposto sobre o valor da terra baseada nas avaliaçóes imobiliárias vigentes; e ii) receita a ser aferida caso imóveis fossem avaliados pelo valor de mercado (perfeita administração tributária). Os resultados desta análise empírica são mostrados na tabela 1 .

Em comparação com o sistema vigente, caracterizado por subavaliaçóes, o valor médio cobrado sobre imóveis de menor valor (primeiro quartil) aumentaria 76\% e sobre imóveis de alto valor (quarto quartil) seria reduzido em 16\%. Com avaliaçóes em nível de mercado, o valor médio cobrado sobre imóveis de baixo valor seria reduzido em 19\% e sobre imóveis de alto valor seria aumentado em $9 \%$.

12. 0 regramento urbanístico muda com frequência. Por exemplo, prédios de quatro pavimentos sem elevador construídos nos anos 1980 compartilham o espaço urbano com prédios novos de quinze ou mais pavimentos nos quais os condôminos desfrutam de áreas de lazer e vários espaços de estacionamento. 
TABELA 1

Alteração média do valor cobrado com a substituição do IPTU por um imposto sobre o valor da terra em Porto Alegre, por classe de imóvel (2003)

(Em \%)

\begin{tabular}{|c|c|c|c|c|c|c|}
\hline \multirow{2}{*}{$\begin{array}{l}\text { Quartil de valor } \\
\text { de imóvel }\end{array}$} & \multicolumn{3}{|c|}{ Sistema vigente } & \multicolumn{3}{|c|}{ Perfeita administração tributária } \\
\hline & Global & Casa & Apartamento & Global & Casa & Apartamento \\
\hline Primeiro & +76 & +260 & +64 & -19 & +160 & -33 \\
\hline Segundo e terceiro & +36 & +58 & -4 & -9 & +70 & -49 \\
\hline Quarto & -16 & +11 & -55 & +9 & +70 & -51 \\
\hline Total & 0 & +39 & -38 & 0 & +78 & -49 \\
\hline
\end{tabular}

Fonte: De Cesare et al. (2003)

Elaboração dos autores.

No entanto, considerando-se apenas as casas, com o sistema vigente, o imposto médio cobrado aumentaria em $39 \%$, sendo $260 \%$ para casas de baixo valor, enquanto os apartamentos teriam uma redução de $38 \%$. Com avaliaçôes a valores de mercado, o imposto médio das casas aumentaria em $78 \%$, sendo $160 \%$ para casas de baixo valor, e o dos apartamentos seria reduzido em $49 \%$.

Ainda pelo estudo de De Cesare et al. (2003), em relação ao padrão construtivo, com as avaliações vigentes, reduçôes tributárias significativas seriam observadas em imóveis classificados como luxo (-75\%) e fino (-35\%). A perda desta arrecadação seria compensada por aumentos exorbitantes no valor do imposto para construçôes de padrão precário (+417\%), de alvenaria mista $(+375 \%)$ e de madeira $(+628 \%)$.

Em função do baixo nível de avaliação dos imóveis de Porto Alegre na época do estudo, foi mais adequado verificar a alíquota necessária para a instituiçâo de um imposto sobre o valor da terra considerando as avaliaçóes a preços de mercado. Neste caso, seria necessária uma alíquota de 3\% (3,5 vezes superior à alíquota original) para compensar a exclusão do valor das construçôes.

Os dados disponibilizados pelo Lincoln Institute of Land Policy (tabela V-3) ${ }^{13}$ e por Carvalho Junior (2017, p. 230) indicam que os terrenos baldios representam pequeno percentual dos imóveis cadastrados em cidades consolidadas, entre 3\% e 12\% em Aracaju, Belo Horizonte, Brasília, Curitiba, Florianópolis, Fortaleza, Porto Alegre, Recife, Rio de Janeiro, Salvador e São Paulo. No caso de elevado nível de desatualização cadastral, esses indicadores podem ainda estar superestimados, visto que parte das áreas cadastradas como terrenos pode ter sido informalmente loteada, construída e ocupada. Em municípios menores com baixa densidade populacional, o número de terrenos baldios tende a ser maior.

\section{ANÁLISE DO DESEMPENHO DOS TRIBUTOS IMOBILIÁRIOS RECORRENTES}

\subsection{IPTU}

O IPTU é um tributo direto, cujo perfil é estritamente local. Visando fortalecer o interesse local e a justiça social imobiliária, os municípios brasileiros são entes federativos que gozam de autonomia fiscal nos termos constitucionais. Desta forma, alíquotas, isenções e outros benefícios fiscais do IPTU são estabelecidos por lei municipal. A magnitude das alíquotas é decorrente da negociação entre governo municipal e seus munícipes sobre a abrangência

13. Disponível em: <https://www.lincolninst.edu/research-data/data/property-tax-latin-america>. 
e a qualidade dos serviços públicos prestados e a capacidade contributiva dos contribuintes. As alíquotas servem, também, para a consecução de objetivos extrafiscais, juntamente com as isenções tributárias e incentivos fiscais.

Com base nas premissas constitucionais, sua estrutura visa inconfundivelmente proporcionar que as famílias mais ricas contribuam mais com o financiamento das despesas públicas realizadas no âmbito local. Isto é decorrente da sua base de cálculo, que é o valor de mercado dos imóveis, incluindo terra e construçôes, bem como da viabilidade de aplicar alíquotas progressivas em razão do valor do imóvel nos termos do art. 156, $\$ 1$, inciso I, da Constituição Federal de 1988 (CF/1988).

Em contrapartida, o IPTU viabiliza a integração entre políticas públicas, fiscais e urbanas. Com o objetivo de promover o uso racional da terra, reduzir a sua ociosidade e desestimular a especulação imobiliária, é viável instituir tanto alíquotas mais elevadas aos terrenos baldios quanto progressivas no tempo, visando ao cumprimento da função social e ambiental da propriedade nos termos do art. $182, \mathbb{\$} 4^{\circ}$, da CF/1988, e do art. 7o, seção III, do Estatuto da Cidade (Lei no $10.257 / 2001$ ).

A receita proveniente desse instrumento é uma fonte importante de recursos para financiamento dos serviços urbanos de forma sustentável. Quanto maior o grau de urbanizaçáo de uma cidade, maior tende a ser o seu potencial de arrecadação. Nesta crise econômica, sem precedentes, produzida pela Covid-19, a arrecadação de impostos menos sensíveis a choques econômicos, como o IPTU, é preponderante para garantir a manutenção de serviços públicos essenciais.

A arrecadação do IPTU teve aumento real de $50 \%{ }^{14}$ entre 2010 e 2019, representando mais de $30 \%$ da receita de impostos municipais e $0,65 \%$ do produto interno bruto (PIB) brasileiro, cifra inclusive um pouco superior à arrecadação do Imposto sobre a Propriedade de Veículos Automotores (IPVA). Este crescimento demonstra o esforço fiscal de um número significativo de municípios na contratação de levantamentos em massa para atualização do cadastro territorial; criação de observatórios do mercado imobiliário; aprimoramento das rotinas internas de atualização contínua do cadastro territorial; reavaliação dos imóveis; e aperfeiçoamento dos sistemas de arrecadação e cobrança do imposto, inclusive apostando na conscientização dos contribuintes por intermédio de programas de educação fiscal.

Não obstante a melhoria observada na última década, análises empíricas relativamente recentes, aplicando métodos distintos, estimam que o potencial de arrecadação do IPTU pode atingir entre 0,90\% e 1,25\% do PIB no Brasil (Carvalho Junior, 2017; De Cesare et al., 2014; Norregard, 2013; Orair e Albuquerque, 2017). Os seguintes aspectos prejudicam o desempenho do IPTU no Brasil.

\subsubsection{Interferência do Poder Legislativo na atualização da base de cálculo do imposto}

A Súmula no 160/1996 do Superior Tribunal de Justiça (STJ) determina que atualizaçóes da base de cálculo do IPTU em percentual superior ao índice oficial de correção monetária necessitam ser realizadas por lei municipal. O IPTU é o único tributo brasileiro cuja aferiçáo da base de cálculo precisa de sanção do Poder Legislativo.

14. Valor da receita do IPTU principal de 2010 indexado pelo Índice Nacional de Preços ao Consumidor Amplo (IPCA), e considerando a receita do IPTU principal de 2019 como 84\% da arrecadação da soma do principal, multas e dívida ativa, conforme a mudança contábil a partir de 2018. 
Além de desrespeitar preceitos constitucionais e legais, a Súmula expóe os gestores públicos a pressóes políticas de grande magnitude para atualizar a base de cálculo do IPTU. A sua desatualização produz injustiça fiscal e contraria o interesse coletivo, ferindo inclusive os princípios da isonomia e da capacidade contributiva contidos na Carta Magna. Enquanto algumas zonas da cidade ou tipos de imóveis valorizam, outras zonas ou tipos de imóveis depreciam. A manutenção de avaliaçôes desatualizadas faz com que uma parcela dos imóveis pague mais do que deveria, prejudicando tipicamente imóveis que desvalorizaram e áreas nas quais não houve investimentos públicos. Em contraste, esta política tende a beneficiar os imóveis que valorizaram no período.

\subsubsection{Falta de regulamentação de prazos máximos entre avaliações para fins de IPTU}

Ciclos máximos entre a reavaliação de imóveis são exigidos por lei não apenas em países desenvolvidos, mas também na África do Sul, Argentina, Chile, Colômbia, Costa Rica, Equador, Guatemala e Uruguai. Em geral, os prazos máximos estabelecidos variam entre dois e cinco anos.

Além de ser imprescindível para a equidade avaliatória, a regulamentação de ciclos entre as avaliaçóes para fins de IPTU contribuiria para minimizar as pressóes sobre os gestores públicos municipais. A inexistência de um dispositivo legal sobre o tema no Brasil resulta em largos períodos entre as avaliaçóes genéricas. Conforme De Cesare (2018a), em 2017, os ciclos avaliatórios do IPTU superavam dez anos em Vitória, São Luiz, Rio Branco, Porto Velho, Teresina, Natal, Belém, Maceió, Porto Alegre e João Pessoa. Além disso, mesmo os que atualizaram em período recente, a maioria estava sem reavaliar por longo período: Curitiba (10 anos), Aracaju e Salvador (16 anos), Rio de Janeiro (20 anos), Recife (24 anos), e Manaus e Porto Alegre (28 anos). Em um caso extremo, João Pessoa está há mais de 40 anos sem promover a atualização completa no valor estimado dos imóveis. Em âmbito federal, houve inclusive a votaçáo do Projeto de Lei do Senado (PLS) no 277/2014 ${ }^{15}$ para alterar a Lei de Responsabilidade Fiscal e tornar obrigatória a atualização das Plantas Genéricas de Valores a cada quatro anos. Porém, como um projeto de lei complementar necessita de quórum qualificado para sua aprovação (41 votos dos senadores e 257 votos dos deputados), ele foi rejeitado já no plenário do Senado Federal por 40 votos favoráveis e 16 contrários em 2015.

\subsection{ITR}

A União tem competência quanto à tributação recorrente da terra rural. Entretanto, a Emenda Constitucional no 42/2003 autorizou o governo federal a transferir por intermédio de acordo a fiscalização e cobrança do ITR aos municípios que assim optarem (art. 153, $\$ 4^{\circ}$, inciso III, da CF/1988). Não é possível, entretanto, alterar os dispositivos legais constantes na Lei Federal no 9.393/1996, tais como as alíquotas, a forma de lançamento do imposto ou os casos de isenção e não incidência. Segundo o então Ministério da Fazenda (Brasil, 2017), aproximadamente 2.100 municípios possuem convênio para fiscalizar e cobrar o ITR.

A arrecadação do ITR representa apenas entre $0,01 \%$ e $0,02 \%$ do PIB. Sua participação na carga tributária é irrisória e vem sendo reduzida de 0,08\% (1999) para 0,06\% (2019). A legislação vigente é obsoleta. De Cesare (2018b) explica que, sem qualquer indício comprovado de eficácia, o ITR foi estruturado com a finalidade essencialmente extrafiscal de promover o aproveitamento eficiente da terra rural (art. 153, $\$ 4^{\circ}$, inciso I, da CF/1988). A base de cálculo é o valor da terra nua (VTN) tributável, desconsiderando as benfeitorias, estabelecido por autoavaliação (art. 8o e art. 10, da Lei Federal no 9.393/1996). A apuração

15. Disponível em: <https://www25.senado.leg.br/web/atividade/materias/-/materia/118636>. 
e o pagamento do ITR são efetuados pelo contribuinte, sujeitos a eventual homologação, por parte do Fisco, posterior ao recolhimento do imposto. Além de a base de cálculo excluir o valor de construçóes, culturas, pastagens e florestas plantadas, as áreas não tributáveis abrangem um amplo número de situaçôes. ${ }^{16}$ Há ainda uma série de condiçôes de isenção e casos de não incidência tributária.

As alíquotas crescem em função da área dos imóveis e do seu grau de subutilização (art. 153, $\$ 4^{\circ}$, da $\mathrm{CF} / 1988$ ), atributos que sáo declarados pelo contribuinte. Considerando que quase todos os contribuintes declarem que suas propriedades têm um grau de utilizaçáo igual ou superior a $80 \%$ e a maioria das propriedades tenha área tributável até 5 mil hectares, as alíquotas de fato se situam entre $0,03 \%$ e $0,3 \%$. A menor alíquota $(0,03 \%)$ é aplicada a imóveis rurais até 50 ha com grau de utilização superior a $80 \%$, corresponde praticamente à isenção e concentra a maioria das declaraçóes. Desta forma, o ITR se torna o "imposto de dez reais" para muitos, que é o valor mínimo legal do lançamento. ${ }^{17}$ Em contraste, a alíquota máxima, que corresponde a 20\% (área acima de 5 mil hectares e grau de utilizaçáo inferior a 30\%), seria confiscatória se fosse efetivamente aplicada. Entretanto, casos da sua aplicação são desconhecidos.

Além disso, é indiscutível a forte heterogeneidade no perfil das áreas rurais no país. Conforme dados do Instituto Brasileiro de Geografia e Estatística (IBGE), a área média de regiôes de agricultura familiar é entre 5,5 ha e 10 ha no Distrito Federal, Alagoas, Pernambuco e Sergipe; e superior a 50 ha nos estados de Mato Grosso, Tocantins, Pará e Acre. Similarmente, é acentuada a variabilidade no tamanho médio dos estabelecimentos classificados na categoria não familiar, cuja média varia de 75 ha (Sergipe) até 1.600 ha (Mato Grosso). Estas diferenças dificultam o estabelecimento de regramento único para o país.

Conforme alerta Carvalho Junior (2018), em estados com crescimento do setor do agronegócio e do comércio de terras rurais, a arrecadação do ITBI - que abrange imóveis urbanos e rurais - é superior à receita do IPTU em: 60\% dos municípios localizados nos estados de Rondônia, Tocantins, Maranhão, Alagoas, Paraná, Mato Grosso do Sul, Mato Grosso e Goiás; 77\% dos municípios localizados no estado de Mato Grosso; e 85\% dos municípios do estado do Tocantins. Isto demonstra que limitar a competência tributária municipal aos imóveis urbanos pode prejudicar a capacidade de geraçáo de receita própria de municípios com características rurais.

Cabe ainda enfatizar que a gestão administrativa do ITR por parte da União é deficiente. O descaso pode estar relacionado ao acesso a outras fontes de receita mais rentáveis e fáceis de administrar. Farias, Silva e Leite (2018) sugerem que o desempenho insatisfatório do ITR está relacionado à falta de fiscalização, decorrente da distância entre contribuintes e o Fisco, resultando na subdeclaração das áreas tributáveis e na superdeclaração do grau de utilização da área, bem como na impunidade decorrente da ausência de fiscalização e descaso na cobrança das dívidas. ${ }^{18}$

A quase ausência de tributação sobre os imóveis rurais representa um grande desperdício da base tributável. Além disto, a segmentação da tributação recorrente imobiliária em dois níveis distintos de governo produz as seguintes disfuncionalidades: i) duplicidades de

16. Incluem: i) áreas de preservação permanente; ii) reservas legais; iii) reservas particulares do patrimônio natural (RPPN); iv) áreas de interesse ecológico; v) servidões ambientais; vi) florestas nativas, primárias ou secundárias em estágio médio ou avançado de regeneração; e vii) áreas alagadas para fins de constituição de reservatório de usinas hidrelétricas.

17. Disponível em: <https://sistemafaeg.com.br/faeg/noticias/agua/receita-quer-aumentar-arrecadacao-do-itr> .

18. A arrecadação do ITR foi de R\$1,303 bilhão em 2015. Entretanto, com base em dados da Procuradoria-Geral da Fazenda Nacional, os autores revelam que aproximadamente 20 mil contribuintes acumulavam uma dívida de ITR de $R \$ 20,80$ bilhões (em média, R\$ 1 milhão por contribuinte). 
esforço fiscal; ii) desperdício de dinheiro público para manutenção de duas bases territoriais distintas (cadastro urbano e cadastro rural); iii) disputas judiciais sobre a classificação da propriedade; e iv) perda do controle pleno municipal sobre o ordenamento territorial, que é de competência exclusiva dos municípios.

\section{CONCLUSÕES E RECOMENDAÇÕES}

Por ser menos sujeito ao impacto de flutuaçôes econômicas, o IPTU é um imposto essencial para manutenção de serviços básicos das cidades. Náo obstante o seu potencial de melhoria, sua importância como fonte de receita cresceu 50\% nos últimos dez anos, resultante exclusivamente de esforço administrativo de diversos municípios. Como explicado anteriormente, o IPTU está inconfundivelmente estruturado para proporcionar que as famílias e indivíduos mais ricos contribuam mais com o financiamento das despesas públicas realizadas no âmbito local.

A luta dos municípios brasileiros para um IPTU vigoroso, em termos tributários, sociais e urbanísticos, foi conquistada paulatinamente. Por exemplo, as restrições impostas pela Súmula no 668 do Supremo Tribunal Federal (STF) que impediam a aplicação de alíquotas progressivas em razão do valor dos imóveis foram superadas pela Emenda Constitucional no 29/2000, que reconheceu constitucionalmente a viabilidade de vincular o IPTU ao princípio da capacidade contributiva, possibilitando a progressividade, a redistribuiçáo de riquezas, a observância do princípio da solidariedade e da realizaçáo do Estado Social Democrático de Direito (Fernandes, 2005).

As alteraçôes tributárias da PEC no 110/2019 abrangem a substituição do IPTU por um imposto sobre o valor da terra e restringem a competência tributária municipal. Na prática, a maioria dos sistemas no âmbito internacional inclui o valor das construçôes na tributação dos imóveis. Os seguintes aspectos podem justificar a resistência a desconsiderar o valor das construçôes na base de cálculo do imposto sobre bens imóveis:

- análises empíricas sobre os seus efeitos na atividade de construção apresentam resultados contraditórios;

- insegurança se a perda de receita gerada pela exclusáo do valor das construçóes pode ser compensada pelo aumento na alíquota;

- receio de confisco;

- receio de efeitos controversos, como superdensificação urbana, que é agravado pela experiência traumática da Covid-19;

- desvinculação entre o imposto e a capacidade contributiva;

- não há vantagem substancial em termos cadastrais, uma vez que o desafio de identificar o contribuinte em áreas irregulares e assentamentos permanece inalterado;

- improbabilidade de simplificações nos sistemas de informação sobre preços praticados; e

- probabilidade de arbitrariedades, iniquidades de caráter avaliatório e falta de transparência.

Ao analisar empiricamente o impacto de excluir o valor das construçóes da base de cálculo do IPTU no município de Porto Alegre para os imóveis residenciais, De Cesare et al. (2003) indicam que, em comparação com o sistema vigente, o imposto sobre o valor da terra iria onerar desproporcionalmente as residências unifamiliares e os imóveis de baixo valor em geral, produzindo aumentos exorbitantes em imóveis de baixo padrão construtivo. Em contraste, o imposto sobre o valor da terra beneficiaria os apartamentos, em especial, imóveis grandes, de alto valor e padráo construtivo fino ou luxo. Analogamente, seria esperado 
um aumento significativo na carga tributária de lojas e demais estabelecimentos mercantis horizontais em oposição à redução significativa em unidades comerciais e de serviços nos condomínios verticais.

Como ilustrado por intermédio de exemplos hipotéticos, imóveis antigos sem elevador ou espaço de estacionamento localizados em condomínios verticais pagariam o mesmo imposto que imóveis novos e modernos, visto que a depreciação e a obsolescência seriam ignoradas.

Além disso, avaliar com precisão o valor de terrenos baldios é problemático, devido ao limitado número de transaçôes em cidades consolidadas. Principalmente em áreas centrais, polos comerciais e outras áreas plenamente densificadas, os lotes estáo edificados. De fato, em cidades maiores, os terrenos baldios representam entre 3\% e 12\% dos imóveis cadastrados. Em decorrência, é provável que regras arbitrárias sejam utilizadas nas avaliaçôes, prejudicando inclusive a eficiência econômica do imposto sobre o valor da terra.

No caso de uma cidade com as características de Porto Alegre, claramente, a alteração da base de cálculo para o valor da terra desconsiderando as construçóes tornaria o imposto regressivo para mais de $95 \%$ dos imóveis cadastrados. Além de onerar os imóveis de menor valor, haveria falta de isonomia entre proprietários de bens de valor idêntico. Dificilmente esta seria uma alternativa plausível para municípios altamente urbanizados e verticalizados.

Para comportamentos especulativos localizados, os municípios contam com instrumentos de política urbana, tais como parcelamento, edificação e utilização compulsórias dos imóveis seguidas da aplicação do IPTU progressivo no tempo nos termos do Estatuto das Cidades. Além disso, a legislação atual permite a aplicação de alíquotas mais elevadas para os terrenos baldios. ${ }^{19}$ Cabe a cada município realizar um diagnóstico para entender os seus desafios e implementar estratégias eficazes de política urbana e tributária.

No tocante às alíquotas, a proposta de estabelecer por lei nacional limites mínimos e máximos é, sem dúvida, um retrocesso. Esta alternativa é utilizada em fases iniciais de processos de descentralização. Os municípios brasileiros são entes federativos, cuja autonomia fiscal foi garantida há mais de trinta anos nos termos constitucionais.

Os municípios devem ter plena autonomia para fixar as alíquotas do IPTU devido: i) ao fato de conhecerem as especificidades locais do mercado imobiliário; ii) à relevância das alíquotas para a concretização da política urbana local e da tributação progressiva; iii) à necessidade de equilíbrio entre a magnitude das alíquotas e o nível das avaliaçóes, que varia fortemente entre municípios e é desconhecido pelo parlamento nacional; e iv) à necessidade de dimensionar as alíquotas de acordo com as exigências orçamentárias. Como discutido anteriormente, é preponderante garantir que a magnitude da carga tributária do IPTU seja decorrente da negociação entre os governos municipais e seus munícipes sobre a abrangência e a qualidade dos serviços públicos prestados.

Visando assegurar o interesse local e a justiça social imobiliária, é imperativo que a fixação das alíquotas do IPTU permaneça sob a plena responsabilidade das Câmaras de Vereadores, que são instrumentalizadas por audiências públicas locais. A heterogeneidade dos municípios brasileiros prejudicaria inclusive a fixação de limites para as alíquotas aplicáveis. Cabe ainda salientar que em países onde há grandes interferências em nível nacional ou estadual no imposto imobiliário local, as receitas tendem a ser baixas. É o caso de Áustria,

19. Além de progressivas em razão do valor do imóvel, as alíquotas podem ser diferenciadas por efeito do uso e da localização (art. 156, § 10, inciso II, da CF/1988). 
Alemanha, Noruega, México e Portugal, países que arrecadaram menos que 0,5\% do PIB em 2018, enquanto a arrecadação média dos países da Organização para a Cooperação e Desenvolvimento Econômico (OCDE) foi de 1,1\% do PIB.

$\mathrm{Na}$ realidade, as competências pelo estabelecimento de alíquotas, isençôes tributárias ou incentivos fiscais, inerentes à autonomia municipal, são essenciais para o cumprimento do Pacto Federativo, art. 1º, da CF/1988. Trata-se de uma cláusula pétrea constitucional (art. 60, $\$ 4^{\circ}, \mathrm{CF} / 1988$ ).

Como leciona Kelsen (1998), a democracia se concretiza com a descentralização do poder, portanto, descentralizar é pressuposto constitucional inegociável em um Estado Social Democrático de Direito.

Embora o fortalecimento do IPTU nos últimos dez anos seja indiscutível, é necessário avançar. Com o objetivo de aumentar a equidade e a eficiência deste importante instrumento, é preciso que a reforma tributária absorva apenas dois aspectos:

- estabeleça o intervalo máximo de quatro anos entre as reavaliaçóes realizadas para fins de IPTU; ${ }^{20}$ e

- autorize os municípios a atualizar o valor venal dos imóveis por decreto ou instruçáo normativa para fins de IPTU, como ocorre com os demais tributos.

Além disso, com o objetivo de viabilizar o ordenamento territorial pleno e garantir a racionalidade administrativa, o mesmo nível de governo deveria ser responsável pela tributação da terra urbana e rural, como ocorre na quase totalidade dos países. Seria, portanto, extremamente oportuno que a reforma tributária transferisse na íntegra a competência tributária do ITR aos municípios. A tentativa de superar esse cenário, permitindo a realização de convênios entre o governo federal e o municipal para o repasse da fiscalização do imposto, mostrou-se insuficiente, na medida em que a estrutura legal do ITR permaneceu inalterada.

Cabe ainda lembrar que a base de cálculo do IPTU inclui o valor da terra. Portanto, os benefícios econômicos do imposto sobre o valor da terra estáo presentes nesta forma de tributação, embora sejam distintos dos efeitos da parcela do imposto que incide sobre o valor das construçôes. Assim, a exclusão do valor das construçôes da base de cálculo do IPTU, além de gerar regressividade, seria um equivocado retrocesso.

\section{REFERÊNCIAS}

ANDELSON, R. V. Land-value taxation around the world. 3rd ed. Oxford: Blackwell Publishers, 2000.

ARNOTT, R. Neutral property taxation. [s.l.]: Institute of Business and Economic Research, 2000. (Seminar Paper Series, n. S00-004).

BENTICK, B. L. The impact of taxation and valuation practices on the timing and efficiency of land use. Journal of Political Economy, v. 87, n. 4, p. 859-868, 1979.

BRASIL. Ministério da Fazenda. ITR Convênio. Consulta entes conveniados. Brasília: Receita Federal do Brasil, 2017.

20. 0 PLS no 277/2014 (complementar) alterava 0 art. 11 da Lei de Responsabilidade Fiscal para estabelecer a atualização da Planta Genérica de Valores em periodicidade não superior a quatro anos. No entanto, o PLS foi negado no plenário do Senado Federal em 5 de agosto de 2015 por um voto (quarenta votos favoráveis e dezesseis desfavoráveis do total de 81 senadores), devido à necessidade de quórum especial, aliada à falta de debates sobre o tema. 
BRUECKNER, J. K. A modern analysis of the effects of site value taxation. National Tax Journal, v. 39, n. 1, p. 49-58, 1986.

CARVALHO JUNIOR, P. H. B. Property tax performance and potential in Brazil. 2017. Dissertation (PhD) - University of Pretoria, 2017.

O Imposto sobre Transmissão de Bens Imóveis (ITBI). In: FAGNANI, E. (Org.).

A reforma tributária necessária: diagnóstico e premissas. 1. ed. Brasília: Anfip; Fenafisco; São Paulo: Plataforma de Política Social, 2018. p. 436-456.

DE CESARE, C. M. Condições básicas para garantir a funcionalidade da tributação recorrente ao patrimônio imobiliário urbano e rural. In: FAGNANI, E. (Org.). A reforma tributária necessária: diagnóstico e premissas. 1. ed. Brasília: Anfip; Fenafisco; São Paulo: Plataforma de Política Social, 2018a. p. 369-393.

. Ponderaçóes sobre avanços preponderantes para o fortalecimento da tributação imobiliária no Brasil. In: MARENCO, A.; NOLL, M. I. (Org.). A política, as políticas e os controles: como são governadas as cidades brasileiras. 1. ed. Porto Alegre: Tomo Editorial, 2018b. p. 65-98.

DE CESARE, C. M. et al. Analyzing the feasibility of moving to a land value-based property tax system: a case study from Brazil. Massachusetts: Lincoln Institute of Land Policy, 2003. (Working Paper).

DE CESARE, C. M. et al. La diversidad del reto: factores críticos del desempeño del impuesto a la propiedad inmobiliaria en Brasil. In: BONET, J. A.; MIRANDA, A. M.; MANNHEIM, C. R. P. (Ed.). El potencial oculto: factores determinantes y oportunidades del impuesto a la propiedad inmobiliaria en América Latina. Washington: Banco Interamericano de Desarrollo, 2014. p. 29-54.

EDWARDS, M. E. Site value taxation in Australia. American Journal of Economics and Sociology, v. 43, p. 481-495, 1984.

FARIAS, F. M. G. B.; SILVA, R. P.; LEITE, A. Z. Imposto sobre a Propriedade Territorial Rural. In: FAGNANI, E. (Org.). A reforma tributária necessária: diagnóstico e premissas. 1. ed. Brasília: Anfip; Fenafisco; São Paulo: Plataforma de Política Social, 2018. p. 394-410.

FERNANDES, C. E. IPTU. Texto e contexto. São Paulo: Quartier Latin, 2005.

FLINT, A. Future of density: affordability, equity, and the impacts of an insidious virus. Massachusetts: Lincoln Institute of Land Policy, 2020.

GEORGE, H. Progreso y miseria. New York: Robert Schalkenbach Foundation, 1996.

KELSEN, H. Teoria geral do direito e do Estado. Tradução de Luís Carlos Borges. 3. ed. São Paulo: Martins Fontes, 1998.

LICHFIELD, N.; CONNELLAN, O. Land value taxation in Britain for the benefit of the community: history, achievements and prospects. Massachusetts: Lincoln Institute of Land Policy, 1997.

LUSHT, K. M. The site value tax and residential development. Melbourne, Australia: Smeal College of Business Administration - The Pennsylvania State University, 1992.

MATHIS, E.; ZECH, C. An empirical test: the economic effects on land value taxation. Growth and Change, v. 13, p. 2-5, 1982. 
MCCLUSKEY, W.; FRANZSEN, R. C. D. Land-value taxation in Australia, Jamaica, Kenya, New Zealand and South Africa. In: IRRV INTERNATIONAL CONFERENCE ON LOCAL GOVERNMENT PROPERTY TAXATION, 5., 1999, Cambridge. Proceedings... Cambridge: [s.n.], 1999. Cambridge, USA, 1999.

MCCLUSKEY, W.; WILLIAMS, B. Introduction: a comparative evaluation. In: MCCLUSKEY, W. (Ed.). Property tax: an international comparative review. England: Ashgate Publishing, 1999. p. 1-31.

MILLS, E. S. The economic consequences of a land tax. In: NETZER, D. (Ed.). Land value taxation: can it and will it work today? Massachusetts: Lincoln Institute of Land Policy, 1998. p. 31-48.

NETZER, D. Land value taxation: can it and will it work today? Massachusetts: Lincoln Institute of Land Policy, 1998. 284 p.

NORREGAARD, J. Taxing immovable property: revenue potential and implementation challenges. Washington: IMF, 2013. (Working Paper, n. 13/129).

OATES, W. E.; SCHWAB, R. M. The impact of urban land taxation: the Pittsburgh experience. National Tax Journal, v. 50, n. 1, p. 1-21, 1997.

ORAIR, R. O.; ALBUQUERQUE, P. H. M. Capacidade de arrecadaçáo do IPTU: estimação por fronteira estocástica com dados em painel. Brasília: Ipea, 2017. (Texto para Discussão, n. 2309).

PINTO, V. C. É preciso substituir o IPTU por um imposto sobre o valor da terra. Caos Planejado, 2020.

PLASSMANN, F. The impact of two-rate taxes on construction in Pennsylvania. Dissertation $(\mathrm{PhD})$ - Virginia Polytechnic Institute and State University, 1997. (Unpublished manuscript).

REECE, B. F. State land taxation: a critical review. [s.l.]: Australian Tax Research Foundation, 1992. (Research Study, n. 15).

TIDEMAN, T. N. Taxing land is better than neutral: land taxes, land speculation, and the timing of development. In: WENZER, K. C. (Ed.). Land value taxation: the equitable and efficient source of public finance. London: Shepheard-Walwyn, 1999. p. 109-133.

TIDEMAN, T. N.; JOHNSON, C. A statistical analysis of graded property taxes in Pennsylvania. Massachusetts: Lincoln Institute of Land Policy, 1995. (Working Paper, 95NT2).

UN-HABITAT. Landy and property tax: a policy guide. Nairobi: United Nations Human Settlements Program, 2011.

VICKREY, W. Propositions relating to site-value taxation. In: WENZER, K. C. (Ed.). Land-value taxation: the equitable and efficient source of public finance. London: Shepheard-Walwyn, 1999. p. 37-45.

WEIR, M.; PETERS, L. E. Development, equity, and the graded tax in the city of Pittsburgh. Property Tax Journal, v. 5, p. 71-84, 1986. 